\title{
Enhancing health service delivery through a University - Local Government partnership model, issues and experiences from Uganda
}

\author{
Commonwealth Journal of Local Governance \\ Issue 13/14: November 2013 \\ http://epress.lib.uts.edu.au/ojs/index.php/cjlg
}

\author{
Gad Ruzaaza Ndaruhutse \\ Uganda Management Institute \\ Kampala \\ Email: gadruzaaza@yahoo.co.uk
}

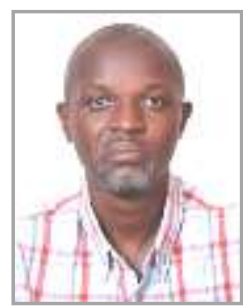

\begin{abstract}
A number of approaches have been adopted in medical education geared towards training health professionals that can improve access to health care by communities most vulnerable to inequalities and injustices in health systems. Relevant health professions education is vital for improvements in health and health care access. A symbiotic medical education can improve the quality of health care and impact on career choice, yet the challenge to sustain equitable access to improved health and healthcare particularly for those most in need remains a major global challenge ( Ssewankambo, 2012). Within a decentralized system, such as in Uganda, Local Governments are mandated to ensure health promotion and equitable healthcare for the population under their jurisdiction. Whereas public service reforms have mainly focused on decentralization and good governance (Mamdani, 2012, Stiglitz, 2012), the role of curriculum reforms in addressing health and health care challenges through needs-based education of health professionals has been largely ignored. Through an analysis of the challenges of health care within a decentralized Local Government setting, this paper, by presenting experiences from one public university in Uganda, reveals how a partnership between Universities and Local Government can go a long way in addressing health disparities and reduction of morbidity and mortality.
\end{abstract}

Key Words: health care, reforms, decentralization, education, Uganda

\section{Background}

A number of approaches have been adopted in medical education geared towards training health professionals that can improve access to health care by communities most vulnerable to health systems inequalities and injustices (Curran and Rourke 2004; O'Toole et al. 2005; Rabow et al. 2007). The most prominent of such approaches is probably Community Based Education (CBE).

The CBE approach first emerged during the 1970's in response to population demand for needs-based education. At the core of CBE was a paradigm shift away from viewing universities as ivory towers.

Previous frameworks for CBE have included a taxonomical classification (Magzoub and Schmidt 2000) or educational objectives based on core competencies (Kligler et al. 2004). An integrated 
partnership between policy makers, health managers, health professions, academic institutions and communities, using a pentagonal model, has been advanced as a transactional model and part of the Towards Unity for Health agenda (Boelen 2000).

Contextually, Mbarara University of Science and Technology (MUST), Uganda's second public university to be opened, at its inception in 1989 embraced CBE as the philosophy for health professions' education within the Faculty of Medicine. The purpose was to establish a curriculum which would facilitate the interaction between the local communities, University lecturers and students, to make them more directed towards the prevailing and emerging needs within Uganda and beyond. Progressively, CBE has been adopted across all Medical Schools in Uganda. MUST continues to tailor its curriculum towards the emerging health and health care needs and demands.

\section{Theoretical background}

Relevant health professions education is vital for improvements in health and health care access (Alwan and Hornby 2002; Maharaj, 2011 ). A symbiotic medical education can improve the quality of health care and impact on career choice (Worley et al. 2006), yet the challenge to sustain equitable access to improved health and healthcare particularly to those most in need remains a major global challenge (Kirigia 2007; Jeppson, 2005). Educational preparation is also a key factor in the sustainability of healthcare practice (Curran and Rourke 2004). The model of medical training at MUST is focused on community based medical curriculum, rural practice and experiences, faculty values and attitudes. The training is based on interactive problem solving, co-learning approach.

Inequitable access to healthcare is still surprising within developing countries. As an example, while remarkable medical advances have been attained at global level, there is an emerging health crisis in sub-Saharan Africa; and it is almost certain that health-related Millennium Development Goals (MDGs) will not be met with work force shortages being a major factor (Dovlo 2007; Magda 2007; Verhallen et al. 2006; WHO 2000)

In most sub-Saharan countries, the health workforce is over-stretched (Jeppsson 2004; Marchal et al. 2005). Chronic deficiencies in training capacity, distribution and skills mix, and retention in the medical and caring professions have left the health services with narrow margins to cope with new challenges (Aitken and Kemp 2003; Huddart et al. 2003). An inadequate health work force has resulted in a complex situation for rural populations, with a demand for need-based approaches in the education of health professionals (Neufeld et al. 1995; Ssengooba etal, 2007) based on the socio economic changes of recent years and resulting health care demands (Cauley et al. 2001), a situation that demands scientific inquiry.

Elsewhere, Zink et al. (2008) have explored how new theories of learning have prompted significant changes in medical education in the United States. Medical educators have responded with curricula 
reform that includes active learning, problem-based learning, and small-group case-based learning local communities and health care workers have in effect become medical educators. This has resulted in expansion of the definition of clinical education and impacted on new career decisions.

\section{Context}

From the 1990s to 2009 the CBE model at MUST laid emphasis on service learning, represented in the acronym COBES (Community Based Education and Service). During 2010, there was curriculum review that incorporated aspects of leadership and put more emphasis on research. Coincidentally all the medical schools in Uganda chose to come together under the MEPI-MESAU consortium in order to build synergy in addressing the prevailing health and healthcare bottlenecks in the county using an educational approach.

At MUST, CBE has grown in its depth and scope through providing the Leadership and Community Placement (LCP) course using a multidisciplinary approach. The course is geared towards instilling leadership knowledge and skills and Primary Health Care management essential for confronting the health challenges of the $21^{\text {st }}$ Century. Students are expected to gain the essential skills and tools required for playing a leadership role in their work environment. In addition to the grounding in primary health care, community diagnosis, health systems and family medicine, students are introduced to leadership and management. A cross-cutting learning outcome is 'health managers who lead' for effective implementation of Primary Health Care and Uganda's minimum health care package. It is also expected that students will have developed a positive attitude towards working in rural / community placements, in turn contributing to the mitigation of health disparity and addressing access, acceptability and affordability of health services.

Systematically, the paper models the Community Based Education (CBE) approach at MUST. The methodology is presented below. The paper describes the conceptual framework that enables understanding of both the experiences and challenges experienced by using such an approach. Strategies to address the challenges of $\mathrm{CBE}$ are provided by defining how curriculum review towards sustainability of the transactional model has been achieved through interactions between the University and health facilities, within a local government context in order to impact on community health and health care needs.

\section{Methodology}

This paper was developed from a theoretical literature review of CBE experiences and their effect on equitable health care. Through a comparative analysis of how CBE has been conceptualised in different settings in comparison with experiences from Mbarara University of Science and Technology (MUST) - Uganda, a conceptual transactional framework of CBE is presented by the 
author. Content analysis as proposed by Neuendorf (2002) was employed to generate themes derived through a review of community based education reports.

\section{Transactional framework of CBE}

The CBE program is enhanced through a transactional relationships illustrated in Figure 1 below with the students at the centre, with its origins in developmental psychology (Sameroff 1975). The transactional model of CBE illustrated below has three key features:

1. Communities are at the centre

2. The triangle indicates that all three components 'external' to the communities influence each other directly, but their relationships are mediated by the communities they serve.

3. The two-way arrows do not symbolise an interaction, in which partners have a dialogue but keep fixed views and positions, but a transaction in which partners change as a result of the process of their involvement with each other.

Figure 1: Transaction framework for CBE

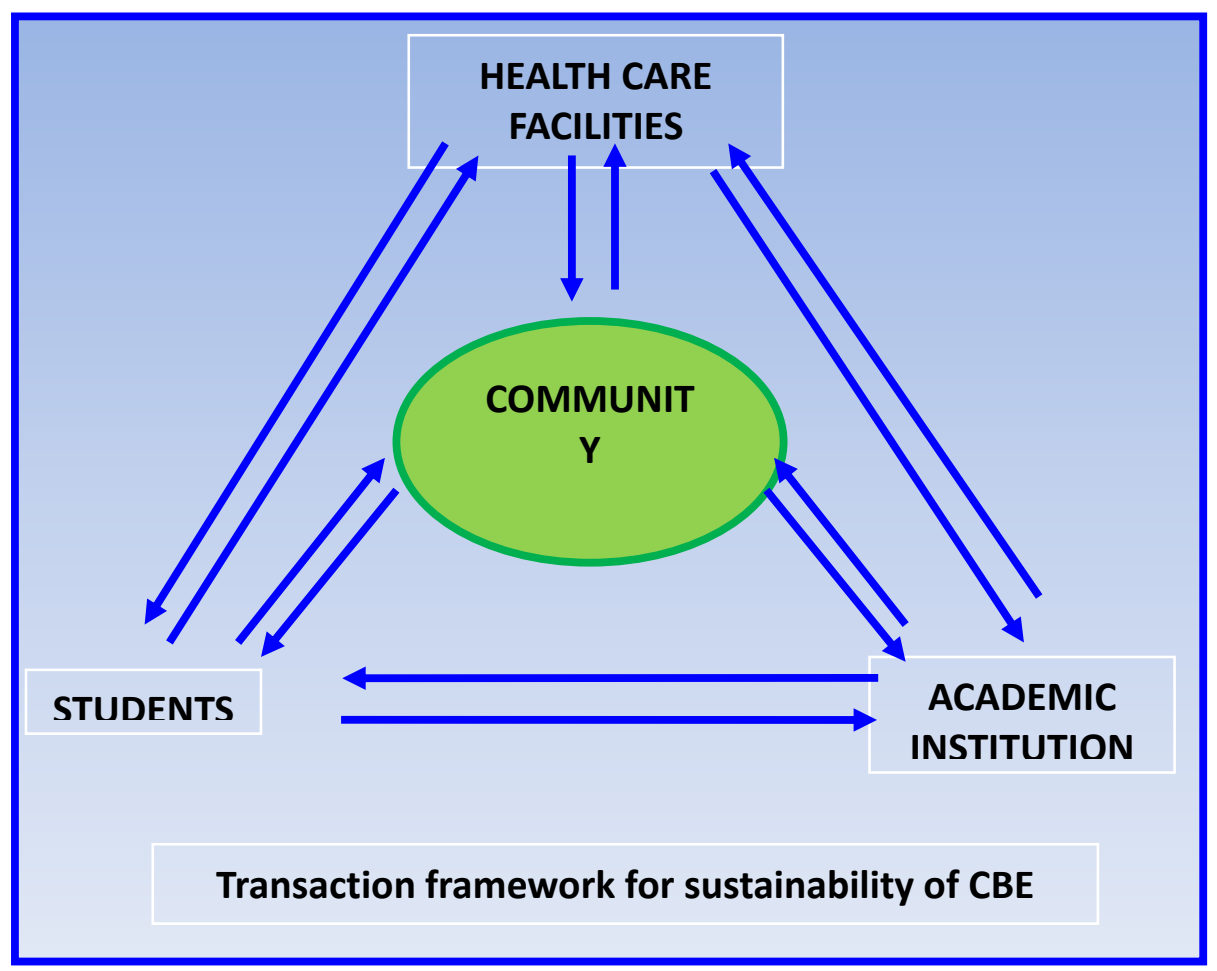

To illustrate the use of this model, CBE is a platform that ensures ongoing interaction between the academic institution, healthcare facilities and students all aimed at targeting improvements in the community. The transactional model represents a dynamic process, and a justification is given below.

\section{Justification of the transactional model}

Access to quality education and health care is a human right, however health challenges and bottlenecks within developing countries remain on the rise (Brenner et al. 2004; Chambers 1994; Rigoli and Dussault 2003; WHO 2000), and emerging advances and health interventions are 
disproportionately targeting the already better served urban areas (Dovlo 2007; Hickey 2005, Jeppson, 2004). Rural areas have found themselves coping through recruitment of semi-trained and untrained health professionals. Whereas promotion of community participation in health promotion is recognized as a strategy for improved health of populations (Carney and Hackett 2008; UN 2001; WHO/UNICEF 1978) relegation of healthcare to untrained populations can be hazardous. CBE presents an optional strategy to mitigate this situation.

Education and training of health professionals should be aligned with the national development plans, including national health plans and human resources for health plans as well as community health needs. Such integrated planning will make it more practical to allocate resources for health development across other sectors including education, public service and finance. The graduates of health training institutions will be able to get promptly recruited in the services and communities where they are most needed. Health training systems should be linked to health services delivery systems so that by the time the graduates complete their training, they are fit for purpose and able to perform amongst their communities. Educational and community-based programs and strategies play an important role in reaching underserved communities. Over the next decade, such strategies will continue to contribute to the improvement of health outcomes (Gamm et al. 2010). Education and community-based programs and strategies are designed to reach people beyond traditional health care settings., for example in schools, work sites, or communities.

Each setting provides opportunities to reach people using existing social structures. This maximizes impact and reduces the time and resources necessary for programme development. People often have high levels of contact with these settings, both directly and indirectly. Programs that combine multiple - if not all 4 - settings can have a greater impact than programmes using only one setting. Using non-traditional settings can help encourage informal information sharing within communities through peer social interaction. Reaching out to people in different settings also allows for greater tailoring of health information and education (Gamm et al. 2010).

Education and training of health professionals could be aligned with national development plans, including national health plans and human resources for health plans as well as community health needs. Such integrated planning will make it more practical to allocate resources for health development across other sectors including education, health, public service, local government and finance. The graduates of health training institutions will be able to get positions in the services and communities where they are most needed. Health training systems should be linked to health services delivery systems so that by the time the graduates complete their training, they are fit for purpose and able to perform on location among their communities. 


\section{Challenges of implementing CBE}

\section{Mission and purpose}

Academic institutions have priorities in research and teaching; health care facilities have a primary role to improve the health of local populations. Although a number of local health care staff acknowledge that teaching and research are part of their role, they find such tasks difficult, citing lack of training or time. Academic staff may not wish to help with local health care when they perceive no direct benefit to themselves or their institution.

\section{Separate organisational accountability}

MUST and its associated teaching hospital are funded by and accountable to the Ministry of Education and Ministry of Health, whereas other local health care facilities are funded and accountable to local government. Prior to the decentralisation policy (Republic of Uganda1999) local health facilities were funded directly by the Ministry of Health. Transactions have been successful due to goodwill on all sides - despite organisational arrangements rather than because of them.

\section{Health service policies and delivery}

Uganda has national policies which have enabled local health services to operate in an integrated and rational approach to common health problems. "Vertical" programmes such as anti-retroviral therapy for HIV/AIDS, whilst very welcome, impose additional stresses on the transaction between health care facilities and the academic institution.

\section{Health service reorganisation}

The management of some of the Lower level health facilities such as Rugazi Health Centre were transferred from Mbarara University to the district health authorities in 2001. This was originally perceived as a potential threat to the continuity of the CBE programme based there. In fact it has been a major benefit as there has been an expansion in staffing and better links with lower health facilities.

\section{Health care facilities with students}

Most health care students have experience as service users before they start their undergraduate studies but are more familiar with hospitals than rural clinics. Students report a relative lack of resources and may feel unable to function well without the variety of investigations and treatment that is available in their base hospital. Time spent working alongside local health staff leads students to understand and respect the clinical skills, management and referral strategies used in peripheral sites. There are opportunities for students and their supervisors to offer suggestions about clinical management strategies to local health care staff.

Whereas some of the health facilities such as Rugazi Health Centre are equipped with facilities for student teaching and accommodation, lower tier health facilities have not been designed with student 
teaching in mind. Securing suitable living accommodation for students close to local health care facilities is a major challenge.

CBE raises community expectations and demands which when ignored lead to fatigue. The result of this is an increasing demand for healthcare providers against limited resources for training. Whereas CBE contributes to responsiveness of the health care system, unless the policy framework is built on addressing the needs of the most deserving populations through, for example social security and insurance schemes, access to healthcare cannot be meaningfully addressed. It is recognized that MUST requires additional resources to further upgrade its curriculum. The undergraduate curriculum should be geared towards strengthening of evidence based education (research on Medical Education), development of a skills laboratory and exploring training undergraduate students using other hospitals in the region in addition to Mbarara Hospital in order to keep pace with the increasing population needs and demands.

\section{CBE transactions - bringing it all together}

In order to expedite the alleviation of health disparities through an educational model, MUST integrated the Leadership Development Program (LDP) into all its undergraduate curricula including CBE in 2009. The LDP course employs a multidisciplinary approach to understanding and addressing of health care challenges in practical community settings. The course is geared towards instilling leadership knowledge and skills essential for confronting the health challenges of the $21^{\text {st }}$ Century. Students are expected to gain the essential leadership and management skills and tools required for playing a change role in their work environment. In addition to the grounding in primary health care, community diagnosis, health systems and family medicine, students are introduced to and participate in leadership and management.

\section{The LDP Course:}

- introduces students to leadership and management in health and the tools required to identify the main health challenges within their area of influence;

- familiarises students with the tools required to focus on priority areas for intervention;

- introduces the tools, skills and techniques required to create solid, logical and coherent action plans that guide students towards achieving measurable results;

- equips students with the tools and techniques for aligning and mobilising populations to address health care challenges;

- introduces the learners to the tools, techniques and strategies for inspiring, and inspired leadership, to address existing and future health care challenges ;

- trains students in communities and rural health units under conditions similar to those in which they will eventually work as qualified doctors; 
- enables students and community members to interact and learn from each other in order to appreciate each other's role in health care and delivery.

A simple core tool used on the course is the challenge model, briefly described below.

\section{The challenge model}

The LDP is organized around the challenge model. The challenge model offers students a systemic approach for working together in multi-disciplinary teams of 6-10 at each placement site to identify one priority health challenge and achieve results as illustrated in the picture below.

The challenge model enables student teams to:

- create shared visions related to the community health challenge they have prioritized;

- agree on a measurable result that the team plans to achieve related to the chosen health challenge;

- assess the current situation by scanning both the internal and external environment. By this the students determine the accurate baseline of the health challenge they will tackle;

- identify obstacles and the root causes: students identify the obstacles that they must overcome to reach a measurable result and carry out a root-cause analysis to identify the underlying causes of obstacles;

- work with communities and stakeholders to define priority actions to address the health challenge;

- involve communities and stakeholders in addressing community health challenges.

Students are placed within different host communities. Particular emphasis is on the needy hard-toreach areas. They also reside at and participate in host health facilities. Students rotate and participate in the health-facility based activities during the mornings and participate in understanding and addressing prevailing and emerging health problems within the communities during the afternoons where applicable, guided by the course guidelines. The students are required to learn and understand the constraints and opportunities that retard or promote good health in the community. They appreciate that communities have the potential to identify and provide solutions to many health problems. Their work should involve, but is not limited to the following broad areas: health systems, child health, growth and development, nutrition, communicable disease control, environmental sanitation, obstetric and surgical care, use and misuse of common drugs and health education. Together with host communities, students identify and prioritise community health and health care issues. They carry out community meetings / seminars and home visits and facilitate discussions on preventive aspects of health care. An added incentive is practicing in a Rural Health facility setting in order to understand constants of rural health and healthcare.

\section{Strategy}


During the community-based activities phase, teams share with each other and with the host healthfacility personnel what they learn throughout the process of implementing their Leadership Project. The course is assessed by MUST Faculty supervisors, in conjunction with Site Supervisors, who play the role of mentors and coaches / tutors to the teams and are expected to meet regularly with students, to review the LDP course content and to support progress. The MUST faculty is expected to constantly follow up the performance of individuals and groups through writing a performance report at every visit. On finalising the community based activities students are expected to present a report, assessed by the faculty that attracts marks that will feature prominently on the academic transcript. The coaches support student teams to prepare the final-results presentation. The course is assessed through group presentations and activity reports.

\section{Course outputs and outcomes}

The LDP course has led to the development of a number of student-led projects across the 30 rural health facility sites within south western Uganda where students undertake the community placement. Students are increasingly motivated by participating in competition for the best prizes, for example the Hillman Medical Education fund. The LDP course has also provided a platform for collaboration with education and healthcare stakeholders most particularly the local government authorities and host health facilities.

\section{Conclusion}

Previous frameworks for CBE have included a taxonomical classification (Magzoub \& Schmidt 2000) or educational objectives based on core competencies (Kristina et al., 2005). An integrated partnership between policy makers, health managers, health professions, academic institutions and communities, using a pentagonal model, has been advanced as part of the Towards Unity for Health agenda (Boelen 2000). However a simpler framework, with communities at the centre, has more resonance and explanatory value in a rural African setting. Practitioners of PHC in Africa are familiar with the image of the cooking-pot supported by three stones used in discussions of nutrition - the pot can only balance if all three stones are present. The CBE framework resembles the cooking-pot analogy. It represents a dynamic system, providing a stable base like the three stone fireplace but constantly developing. 'Transactions' are relationships between people in an enterprise which involve mutual change. Those involved in CBE should expect to welcome and enjoy transactions, experiencing change and development as they learn from each other.

Examples presented illustrate that when communities are at the centre the links between the other components of the framework become stronger. It is suggested that the triangular transactional framework involving students, lower health facilities and academia described above is a useful way of perceiving the challenges to sustainability of $\mathrm{CBE}$ which could provide impetus to quality health care within local governments in a most sustainable manner. 


\section{References}

Aitken, J, M and and J Kemp. (2003) HIV/AIDS, equity and health sector personnel in Southern Africa in EQUINET Discussion paper Harare: EQUINET.

Alwan, A., and P. Hornby (2002) "The implications of health sector reform for human resources development." Bulletin of the World Health Organization 80:56 - 60.

Boelen, C. (2000) "Towards Unity for Health: Challenges and Opportunities for Partnership in Health Development." Geneva: WHO.

Brenner, J, L, F Bagenda, V Nilah N, G Ruzaaza, J Kabakyenga, and N Singhal. (2004) "A situational Analysis of Child Health in CPS - MUST Project Communities in South western Uganda." Paediatrics Child Health 9.

Carney and Hackett (2008) Richards 2001; UN 2001; UNMillennium Project 2001; WHO/UNICEF 1978)

Cauley, Kate, Annette Canfield, Carla Clasen, Sheranita Hemphill, Dobbins, , , Elvira Jaballas, and Gordon Walbroehl. (2001) "Service Learning: Integrating Student Learning and Community Service." Education for Health 14:173 - 181.

Chambers, Robert. (1994) "Participatory Rural Appraisal (PRA): analysis of experience." World Development: 1253 - 1268.

Curran, Vernon, and James Rourke. (2004) "The role of medical education in the recruitment and retention of rural physcians." Medical Teacher 26:265-272.

Dovlo, Delanyo. 2007. "Migration of Nurses fron Sub - Saharan Africa: a review of issues " Health Research and Educational Trust.

Gamm L, Castillo G, Williams L. Education and community-based programs in rural areas: A literature review. In: Rural Healthy People 2010: A companion document to Healthy People (2010) Volume 3. Gamm L,

Hutchison L, editors. College Station, TX: The Texas A\&M University System Health Science Center, School of Rural Public Health, Southwest Rural Health Research Center; 2004. p.167-86.

Hickey, Samuel (2005). Conceptualising the politics of social protection in Africa, A. Barrientos and D. Hulme Social Protection for the Poor and Poorest. Risk, Needs and Rights. Palgrave/Macmillan

Huddart, and et al. (2003) "The health sector. Human resource crisis in Africa: An Issues paper. Support for analysis and research in Africa (SARA))." Washington: Academy for Educational Development.

Jeppsson, Anders. (2004) "Decentralization and National Health Policy Implementation in Uganda - a Problematic Process." Lund, Sweden: Lund University Media-Tryk.

Jeppsson, Anders, Harriet Birungi, Per-Olof Östergren, and Bo Hagström. (2005) "The global-local dilemma of a Ministry of Health: Experiences from Uganda." Health Policy 72:311-320.

Kirigia, Joses, Muthuri. (2007) "The economic cost of health proffessionals brain drain in the African region: A case study." Pp. 38 - 40 in Afican Health Monitor - A magazine of World Health Organisation Regional office for Africa.

Kligler, Benjamin, Victoria Maizes, Steven Schachter, Constance Park, Tracy Gaudet, Rita Benn, Roberta Lee, and Naomi Rachel Remen. (2004) "Core Competencies in Integrative Medicine for Medical School Curricula: A Proposal." Acad Med 79:521-531.

Kristina DN, Majoor GD, and Van der Vleuten CP. (2005) "Defining generic objectives for community based education in undergraduate medical programmes." Medical Education 8:510-521.

Magda, Awases. (2007) "Migration of skilled health proffessional in the African region: an overview." Pp. 28 33 in African Health Monitor - A magazine of the World Health Organisation Regional office for Africa.

Magzoub, ME, and HG Schmidt. (2000) "A taxonomy of community-based medical education." Academic Medicine 75:699-707.

Maharaj, S., R., (2011) Healthcare for the poor and dispossessed from Alma-Ata to the millennium development goals, West Indian Medical journal

Mamdani, 1212, a critique of Joseph Stiglitz, "Market Failures in the Financial System: Implications for Financial Sector Policies, especially in Developing Countries," Joseph Mubiru Memorial lecture (17 Jul 2012 , Munyonyo - Kampala, Uganda) 
Marchal, Bruno, Vincent Browere De, and Guy Kegels. 2005. "HIV/AIDS and the health workforce crisis: what are the next steps?" Tropical Medicine and International Health 10:300 - 304.

Neufeld, Victor, et al. Leadership for change in the education of health professionals; Leadership for change in the education of health professionals. Network Publications, 1995.

Neuendorf, K.A., (2002) The content analysis guidebook, Sage Publications, London

O'Toole, TP, N Kathuria, M Mishra, and D Schukart. (2005) "Teaching professionalism within a community context: perspectives from a national demonstration project." Acad Med 80:339-43.

Rabow, WM, J Wrubel, and RN Remen. 2007. "Authentic community as an educational strategy for advancing proffessionalism: s nstionsl rvslustion of the Healer's Art course." J Gen Intern Med 22:1422-8.

Rigoli, F., and G. Dussault. (2003) "The interface between health sector reform and human resources in health." Hum Resour Health 1:9.

Sameroff, A (1975) Transactional models in early social relations, Human Development, 18, 65-79

Ssewankambo, (2012) Medical Education and Services to all Uganda's (MESAU) News Letter

Ssengooba, Freddie, Syed Rahman, Charles Hongoro, Elizeus Rutebemberwa, Ahmed Mustafa, Tara Kielmann, and Barbara McPake. (2007) "Health sector reforms and human resources for health in Uganda and Bangladesh: mechanisms of effect." Human Resources for Health 5:3.

Stiglitz, J., 2012, "Market Failures in the Financial System: Implications for Financial Sector Policies, especially in Developing Countries, "Joseph Mubiru Lecture, Bank of Uganda, Munyonyo Conference Centre, Kampala, July 16, 2012, 28 pp.

UNMillennium Project. (2001) "Investing in Development: a practical plan to acheive Millennium Development Goals." New York: United Nations.

Verhallen, M, D Giusti, and N Bolan. (2006) "Addressing the Human Resource in Health Crisis: Empowering the Private Not for Profit Health Training Institutions to Play Their Role." Global Health Council.

WHO. (2000) "Health Systems: Improving Performance." in The World Health Report 2000. Geneva: World Health Organisation.

WHO/UNICEF. 1978. "Primary health care." in The Alma Ata conference. Geneva.

Worley, Paul, David Prideaux, Roger Straser, Anne Magarey, and March Robyn.( 2006) 'Empirical evidence for symbiotic medical education: a comparative analysis of community and tertiary based programmes' Medical Education 40:109 - 116.

Zink, Terese, Gwen W Halaas, Deborah Finstad, and Kathleen B. (2008) "The rural physician association program: the value of immersion learning for third - year medical students, " The Journal of Rural Health 24:353-359. 